\title{
EFFECT OF ALKALINE SOLUTIONS ON ENGINEERING PROPERTIES OF ALKALI-ACTIVATED GGBFS PASTE
}

\section{Tzong-Ruey Yang}

Department of Construction Engineering, National Taiwan University of Science and Technology, Taipei City, Taiwan, R.O.C.

Ta-Peng Chang

Department of Construction Engineering, National Taiwan University of Science and Technology, Taipei City, Taiwan, R.O.C., tpchang@mail.ntust.edu.tw

Bo-Tsun Chen Department of Construction Engineering, National Taiwan University of Science and Technology, Taipei City, Taiwan, R.O.C.

Jeng-Ywan Shih

Department of Chemical Engineering, Ming Chi University of Technology, New Taipei City, Taiwan, R.O.C.

Wei-Lun Lin

Department of Construction Engineering, National Taiwan University of Science and Technology, Taipei City, Taiwan, R.O.C.

Follow this and additional works at: https://jmstt.ntou.edu.tw/journal

Part of the Civil and Environmental Engineering Commons

\section{Recommended Citation}

Yang, Tzong-Ruey; Chang, Ta-Peng; Chen, Bo-Tsun; Shih, Jeng-Ywan; and Lin, Wei-Lun (2012) "EFFECT OF ALKALINE SOLUTIONS ON ENGINEERING PROPERTIES OF ALKALI-ACTIVATED GGBFS PASTE," Journal of Marine Science and Technology. Vol. 20: Iss. 3, Article 10.

DOI: 10.51400/2709-6998.1809

Available at: https://jmstt.ntou.edu.tw/journal/vol20/iss3/10

This Research Article is brought to you for free and open access by Journal of Marine Science and Technology. It has been accepted for inclusion in Journal of Marine Science and Technology by an authorized editor of Journal of Marine Science and Technology. 
EFFECT OF ALKALINE SOLUTIONS ON ENGINEERING PROPERTIES OF ALKALIACTIVATED GGBFS PASTE

\section{Acknowledgements}

This work was carried out under the financial supports of the Taiwan Building Technology Center (TBTC) of National Taiwan University of Science and Technology (Taiwan Tech). Courtesy of some experimental data from Mr. Wei-Lun Lin is also appreciated. 


\title{
EFFECT OF ALKALINE SOLUTIONS ON ENGINEERING PROPERTIES OF ALKALI-ACTIVATED GGBFS PASTE
}

\author{
Tzong-Ruey Yang ${ }^{1}$, Ta-Peng Chang ${ }^{1}$, Bo-Tsun Chen ${ }^{1}$, Jeng-Ywan Shih ${ }^{2}$, \\ and Wei-Lun Lin ${ }^{1}$
}

Key words: alkaline solution, thermal conductivity, volumetric heat capacity, alkali-activated, slag.

\begin{abstract}
In this study, two kinds of alkaline solutions, sodium hydroxide $(\mathrm{NaOH})$ and sodium silicate $\left(\mathrm{Na}_{2} \mathrm{SiO}_{3}\right)$, with three dosages of $0.5,1.0$ and $1.5 \%$ by weight were used to produce the alkali-activated ground granulated blast furnace slag (GGBFS) paste at three different liquid-solid ratios by weight of $0.45,0.5$ and 0.55 . Most engineering properties of the paste were examined at age of $3,7,14,28$ and 56 days. Experimental results show that a mixed alkaline solution of sodium hydroxide and sodium silicate is necessary to produce an alkaliactivated GGBFS paste with adequate workability and strength. Both the liquid-solid ratio and the amount of the alkaline solution affect the compressive strength in the range of 30.38 to $166.22 \mathrm{MPa}$ at age of 28 days. After curing 28 days, alkali-activated GGBFS paste has the coefficient of thermal conductivity and volumetric heat capacity in range of $0.585-0.791 \mathrm{~W} / \mathrm{m} \cdot \mathrm{K}$ and $1.583-1.8 \mathrm{~J} / \mathrm{m}^{3} \cdot \mathrm{K}$, respectively, which are lower than/close to those of normal weight concrete and thus can be used as a proper material for heat insulation. The microstructural porosity of alkali-activated GGBFS paste is closely related to its engineering and thermal properties.
\end{abstract}

\section{INTRODUCTION}

In 1992, the common consensus of suitable environment was established in "Agenda 21." Four major waste-related program areas were also suggested in order to provide a comprehensive and environmentally responsive framework for managing municipal solid wastes: (1) Minimizing wastes; (2)

Paper submitted 03/25/11; revised 03/12/12; accepted 05/01/12. Author for correspondence: Ta-Peng Chang (e-mail: tpchang@mail.ntust.edu.tw).

${ }^{1}$ Department of Construction Engineering, National Taiwan University of Science and Technology, Taipei City, Taiwan, R.O.C.

${ }^{2}$ Department of Chemical Engineering, Ming Chi University of Technology, New Taipei City, Taiwan, R.O.C.
Maximizing environmentally sound waste reuse and recycling; (3) Promoting environmentally sound waste disposal and treatment and (4) Extending waste service coverage [18]. Therefore, many industry wastes are thus required to be reused in construction engineering for environment sustainable consideration. The ground granulated blast furnace slag (GGBFS) with major components of $\mathrm{SiO}_{2}, \mathrm{CaO}, \mathrm{Al}_{2} \mathrm{O}_{3}$ and the other oxides is a by-product from the iron and steel industry. A large quantity of GGBFS is produced every year in Taiwan and needs to be properly treated to avoid potential environmental problems. In general, GGBFS is commonly reused to replace portion of cement in making concrete, especially the high strength concrete (HSC) and the high performance concrete (HPC), on account for alleviating environmental impact, increasing workability and durability, and saving cost $[1,3,15$, 20]. In recently years, the alkali-activated GGBFS paste by mixing of GGBFS and alkaline solutions has been found to be a novel material with excellent compressive strength and fire-resistance capability [10, 14, 16, 17, 23]. The GGBFS particle is dissolved in the alkaline solution to form $\mathrm{Si}$ and $\mathrm{Al}$ gel on the surface of particle. Then, a polycondensation process for polysialate is occurred and forms the networked structure as the empirical form $\mathrm{M}_{\mathrm{n}}\left[-\left(\mathrm{SiO}_{2}\right)_{\mathrm{Z}}-\mathrm{AlO}_{2}\right]_{\mathrm{n}} \cdot \mathrm{wH}_{2} \mathrm{O}$ $[6,7]$, where $\mathrm{M}$ indicates the positive ion of metal, $\mathrm{n}$ indicates the degree of polymerization, $\mathrm{z}$ indicates the ratio of silica to aluminum and normally equals to the value between 1 to 3 .

Previous studies investigated the ratio of liquid to solid and the amount of alkaline solution are the significant factors to affect the mechanical properties of alumino-silicate based/ashbased geopolymers $[19,21]$. The ratio of liquid to solid is defined as the weight ratio of alkaline solutions to waste alumino-silicate materials. The volume shrinkage of geopolymer paste during harden processing of dehydration is related to the ratio of liquid to solid. Lower ratio of liquid to solid may reduce the shrinkage of geopolymer paste. Xu et al. indicated that the ratio of liquid to solid usually affects the reaction of cement polymerization and its engineering properties. The relationship between the ratio of liquid to solid and the precipitation of aluminum and silica ions is linear. As the ratio of liquid to solid is increasing, the initial and final setting times of 
Table 1. Physic properties of GGBFS.

\begin{tabular}{cccc}
\hline \multirow{2}{*}{$\begin{array}{c}\text { Bulk density } \\
\left(\mathrm{g} / \mathrm{cm}^{3}\right)\end{array}$} & $\begin{array}{c}\text { Fineness } \\
\left(\mathrm{cm}^{2} / \mathrm{g}\right)\end{array}$ & \multicolumn{2}{c}{ Activity index } \\
\cline { 3 - 4 } & 6000 & 89.5 & 28 days \\
\hline 2.8 & & 819.6 \\
\hline
\end{tabular}

Table 2. Chemical compositions of GGBFS.

\begin{tabular}{cccccc}
\hline $\mathrm{SiO}_{2}$ & $\mathrm{Al}_{2} \mathrm{O}_{3}$ & $\mathrm{Fe}_{2} \mathrm{O}_{3}$ & $\mathrm{CaO}$ & All other oxides & L.O.I. \\
\hline 33.47 & 14.79 & 0.40 & 41.61 & 9.15 & 0.58 \\
\hline
\end{tabular}

geopolymer paste are also increased. The addition of alkali-activated concentration is an important control factor to affect other Si gel generation. Komnitsas et al. [9] indicate the hydroxide concentration is a control vital factor of strength. Their results show that a high alkali hydroxide concentration could obtain a high compressive strength, but when excess concentration is used, a decrease of the final strength occurs. Brough et al. [5] research results also show that although an optimal high alkali hydroxide concentration can significantly increase the strength and shorten the setting time, but it is liable to let the specimen becoming brittle and vulnerable to weathering, although this fault can be improved by adding other mineral additive or curing in water. Thus, an optimal high concentration of alkaline could accelerate the polymerization reaction and increase mechanical properties, but excessive concentration beyond optimal value also decreases the strength and durability.

On the other hand, both the thermal conductivity and volumetric heat capacity of geopolymer paste are the crucial factors to access its ability for heat transfer and suitability for heat insulation $[2,4,8,13,22]$. A material with lower thermal conductivity can reduce heat losses, save energy and serve as a good potential candidate for thermal isolation and/or fire resistant materials of structures. A material with high volumetric heat capacity indicates that a high heat energy from outer resource is needed to increase the inner temperature of material.

In this study, effects of the two kinds and three amounts of dosage of alkaline solutions, sodium hydroxide $(\mathrm{NaOH})$ and sodium silicate $\left(\mathrm{Na}_{2} \mathrm{SiO}_{3}\right)$, on the engineering and thermal properties of alkali-activated ground granulated blast furnace slag (GGBFS) paste were investigated. Detailed of experimental program and test results are described in the following sections.

\section{EXPERIMENT WORK}

\section{Raw Materials}

The characteristics of raw materials of alkali-activated GGBFS paste used in this study are described as follows:

(1) Ground granulated blast furnace slag (GGBFS): A domestic product from CHC Resources Corporation, Taiwan, has the physic properties and chemical compositions as
Table 3. Chemical compositions of alkaline solutions.

\begin{tabular}{ccc}
\hline & $\begin{array}{c}\text { Sodium hydroxide } \\
(\mathrm{NaOH})\end{array}$ & $\begin{array}{c}\text { Sodium silicate } \\
\left(\mathrm{Na}_{2} \mathrm{SiO}_{3}\right)\end{array}$ \\
\hline $\mathrm{NaOH}$ & 98.2 & --- \\
$\mathrm{NaCO}_{3}$ & 0.165 & --- \\
$\mathrm{NaCl}$ & 0.0135 & --- \\
$\mathrm{Fe}$ & 0.0004 & $<0.02$ \\
$\mathrm{SiO}_{2}$ & --- & 29.2 \\
$\mathrm{Na}_{2} \mathrm{O}$ & --- & 8.19 \\
\hline
\end{tabular}

shown in Tables 1 and 2, respectively.

(2) Sodium hydroxide $(\mathrm{NaOH})$ solution: The $\mathrm{NaOH}$ solution with $5 \mathrm{M}$ concentration was prepared by mixing the solid sodium hydroxide flake with deionized water in the laboratory with its chemical compositions shown in Table 3.

(3) Sodium silicate solution (water glass) $\left(\mathrm{Na}_{2} \mathrm{SiO}_{3}\right)$ : A commercial sodium silicate solution produced in Taiwan has the chemical composition as shown in Table 3.

\section{Mixture Proportions}

Previous study [11] has indicated that an alkaline solution with only sodium hydroxide $(\mathrm{NaOH})$ results in quick setting and high strength of alkali-activated GGBFS paste. On the other hand, an alkaline solution with only sodium silicate solution $\left(\mathrm{Na}_{2} \mathrm{SiO}_{3}\right)$ renders the alkali-activated GGBFS paste into a good workability with hardly setting state and low strength. Thus, a mixed alkaline solution of sodium hydroxide and sodium silicate is necessary to produce an alkali-activated GGBFS paste with adequate workability and strength. By adjusting merits of both solutions to obtain an applicable workability and strengths of alkali-activated GGBFS paste from quite a few preliminary trials, this study finally adopts two parameters, the weight ratio of liquid to solid (GGBFS) $\left(R_{L S}\right)$ and weight percentage of sodium oxide $\left(\mathrm{Na}_{2} \mathrm{O}\right)$ to solid (GGBFS) $(N)$, to conduct the investigation. Nine mixtures of alkali-activated GGBFS paste based on three values of $R_{L S}$, $0.45,0.50$ and 0.55 , and three percentages of $N, 0.5,1.0$ and $1.5 \%$, were used. All the ingredients of nine mixtures, as shown in Table 4, were calculated from the following three equations:

$$
\frac{W_{N O}}{W_{s l}}=N
$$

$$
\frac{W_{S H}+W_{S S}}{W_{s l}}=R_{L S}
$$

$$
\frac{W_{S H}}{\gamma_{S H}}+\frac{W_{S S}}{\gamma_{S S}}+\frac{W_{s l}}{\gamma_{s l}}=1
$$

where $W_{N O}, W_{S H}, W_{S S}$ and $W_{s l}$ are weights, sodium oxide solution, sodium hydroxide solution, sodium silicate solution 
Table 4. Mix proportion of alkali-activated GGBFS paste.

\begin{tabular}{|c|c|c|c|c|c|}
\hline \multirow[b]{2}{*}{ Designation } & \multirow[b]{2}{*}{$R_{L S}$} & \multirow[b]{2}{*}{$N(\%)$} & \multirow{2}{*}{$\begin{array}{c}\text { Solid } \\
W_{s l}(\mathrm{GGBFS}) \\
\left(\mathrm{kg} / \mathrm{m}^{3}\right)\end{array}$} & \multicolumn{2}{|c|}{ Liquid } \\
\hline & & & & $\begin{array}{c}W_{S S} \text { (Water glass) } \\
\left(\mathrm{kg} / \mathrm{m}^{3}\right)\end{array}$ & $\begin{array}{c}W_{S H}(5 \mathrm{M} \mathrm{NaOH}) \\
\left(\mathrm{kg} / \mathrm{m}^{3}\right)\end{array}$ \\
\hline LS45N05 & 0.45 & 0.5 & 1743 & 719 & 65 \\
\hline LS45N10 & 0.45 & 1.0 & 1730 & 649 & 130 \\
\hline LS45N15 & 0.45 & 1.5 & 1718 & 580 & 193 \\
\hline LS50N05 & 0.50 & 0.5 & 1656 & 766 & 62 \\
\hline LS50N10 & 0.50 & 1.0 & 1644 & 699 & 123 \\
\hline LS50N15 & 0.50 & 1.5 & 1633 & 633 & 183 \\
\hline LS55N05 & 0.55 & 0.5 & 1577 & 808 & 59 \\
\hline LS55N10 & 0.55 & 1.0 & 1567 & 744 & 117 \\
\hline LS55N15 & 0.55 & 1.5 & 1556 & 681 & 175 \\
\hline
\end{tabular}

and GGBFS in units of $k g$ in sodium hydroxide solution, respectively; $\gamma_{S H}, \gamma_{S S}$ and $\gamma_{S l}$ are bulk density of sodium hydroxide solution, sodium silicate solution and GGBFS in units of $\mathrm{kg} / \mathrm{m}^{3}$, respectively.

\section{Specimen Preparation and Testing Program}

After the GGBFS and 5M NaOH solution had been firstly mixed together in a mixer for about 5 minutes, the sodium silicate solution then was gradually added into the mixer and mixed for another 5 minutes. The flow test and setting time test of fresh alkali-activated GGBFS paste were determined afterwards according to ASTM C230M and ASTM C807 test methods, respectively. After the flow test, the cubic specimens $(50 \times 50 \times 50 \mathrm{~mm})$ and cylinder specimens $(\phi 50 \times 100$ $\mathrm{mm}$ ) with each mix proportion were cast. After one day, these specimens were demoulded and cured at room temperature until the ages of 3, 7, 14, 28 and 56 days for uniaxial compressive strength test and dynamic modulus of elasticity and the age of 28 days for testing coefficient of thermal conductivity and volumetric heat capacity. In total, 135 cubic specimens and 27 cylindrical specimens were used.

The uniaxial compressive strength test and dynamic modulus of elasticity test were conducted in accord with ASTM C39 and ASTM C215 Standards, respectively. The equipment of ISOMET 2104 with surface probe was used to measure the coefficient of thermal conductivity and volumetric heat capacity of alkali-activated GGBFS paste. The ISOMET 2104, manufactured by Applied Precision Ltd., Slovakia, is a portable measuring instrument for direct measurement of heat transfer properties of a wide range of isotropic materials including cellular insulating materials, plastics, glasses and minerals with a dynamic measurement method that reduces the time of thermal conductivity measurements to 10-16 minutes. Finally, the microstructures of each specimen with different mix proportions were also investigated by using scanning electron microscope (SEM) and used to correlate the thermal and engineering properties of alkali-activated GGBFS paste.
Table 5. Flow value and setting of each mix proportion of alkali-activated GGBFS paste.

\begin{tabular}{cccc}
\hline Designation & $\begin{array}{c}\text { Flow value } \\
(\%)\end{array}$ & $\begin{array}{c}\text { Initial setting } \\
\text { time (min) }\end{array}$ & $\begin{array}{c}\text { Final setting } \\
\text { time (min) }\end{array}$ \\
\hline LS45N05 & 70 & 380 & 440 \\
LS45N10 & 95 & 270 & 335 \\
LS45N15 & 105 & 20 & 35 \\
LS50N05 & 95 & 540 & 605 \\
LS50N10 & 140 & 370 & 455 \\
LS50N15 & 150 & 65 & 80 \\
LS55N05 & 115 & 650 & 735 \\
LS55N10 & $*$ & 510 & 650 \\
LS55N15 & $*$ & 170 & 185 \\
\hline
\end{tabular}

* The fresh mix overflows the circumferential margin of round flow test table.

\section{EXPERIMENT RESULTS AND DISSCUSSION}

\section{Workability}

The flow test and setting time test were used to evaluate workability of alkali-activated GGBFS paste. Their results are shown in Table 5, Figs. 1 and 2. The smallest values of flow test of $70 \sim 105 \%$ occur at the lowest $R_{L S}$ of 0.45 . With the increase of $R_{L S}$ from 0.45 to 0.55 , a substantial increase of flow test value is observed. Increasing the $N$ values from 0.5 to $1.5 \%$ tends to increase the flow test value for all three sets of mixtures $\left(R_{L S}=0.45,0.50\right.$ and 0.55$)$. The smallest values of initial setting times of 20 380 minutes and final setting times of 35 440 minutes also occur at the lowest $R_{L S}$ of 0.45 . With the increase of $R_{L S}$ from 0.45 to 0.55 , a substantial increase of flow test value up to $170 \sim 650$ minutes for initial setting time and 185 735 minutes for final setting time is observed. However, on the contrary, increasing the $N$ values from 0.5 to $1.5 \%$ tends to substantially decrease the both setting times for all three sets of mixtures $\left(R_{L S}=0.45,0.50\right.$ and 0.55$)$. 
Table 6. Compressive strengths of each mix proportion of alkali-activated GGBFS paste.

\begin{tabular}{lrrrrr}
\hline & \multicolumn{5}{c}{$\begin{array}{c}\text { Compressive strength (Unit: MPa) } \\
\text { (average of three specimens) }\end{array}$} \\
\cline { 2 - 6 } Designation & 3 days & 7 days & 14 days & 28 days & 56 days \\
\hline LS45N05 & 2.96 & 3.08 & 8.16 & 46.96 & 78.47 \\
LS45N10 & 40.40 & 57.36 & 73.93 & 74.06 & 78.89 \\
LS45N15 & 61.18 & 74.77 & 97.28 & 104.05 & 110.36 \\
LS50N05 & 1.73 & 3.03 & 10.48 & 49.14 & 84.37 \\
LS50N10 & 24.65 & 39.09 & 82.57 & 108.70 & 112.06 \\
LS50N15 & 53.39 & 64.48 & 91.58 & 166.22 & 166.32 \\
LS55N05 & 1.20 & 3.16 & 5.76 & 30.38 & 61.36 \\
LS55N10 & 2.54 & 25.73 & 30.86 & 57.68 & 76.75 \\
LS55N15 & 51.95 & 65.61 & 79.93 & 135.63 & 146.33 \\
\hline
\end{tabular}

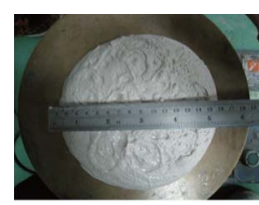

(a) LS45N05

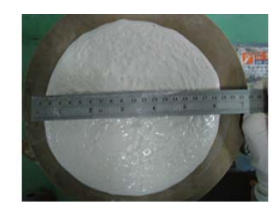

(b) LS50N05

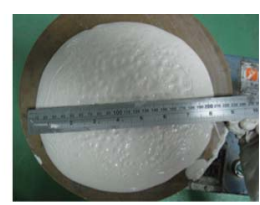

(c) LS55N05
Fig. 1. Typical flow test photo of alkali-activated GGBFS paste with different ratios of liquid to solid $(N=0.5 \%)$.

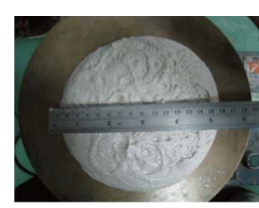

(a) $N=0.5 \%$

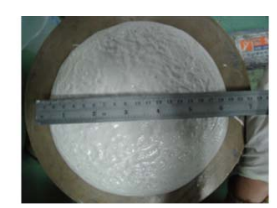

(b) $N=1.0 \%$

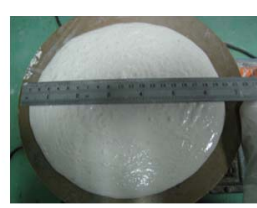

(c) $N=1.5 \%$
Fig. 2. Typical flow test photo of alkali-activated GGBFS paste with $\boldsymbol{R}_{L S}$ of 0.45 and different additions of alkaline solution.

The reason for such opposite variation of these two workability indices could be attributed to the fact that the increase of $R_{L S}$ means an increase of water in the fresh paste such that the flow test values apparently increase too. But too much water tends to dilute the concentration of alkali-activated solution and, subsequently, postpone the alkali-activating speed and increase setting time. On the other hand, increase $N$ values from 0.5 to $1.5 \%$ will thicken the concentration of alkaline solution to expedite alkali-activating reaction and reduce both setting times.

\section{Compressive Strength}

The results of uniaxial compressive strengths for all mixtures at ages of 3, 7, 14, 28 and 56 days are summarized in Table 6 and shown in Figs. 3 and 4. The highest values at age of 28 and 56 days occur at three mixture sets of $R_{L S}$ of 0.50 , rather than 0.45 or 0.55 , in which a substantial increase of strength from 49.14 to $166.22 \mathrm{MPa}$ at 28 days and from 84.37 to $166.32 \mathrm{MPa}$ at 56 days with the increase of $N$ values from 0.5 to $1.5 \%$. The increase ratios are in the range from $97.1 \%$

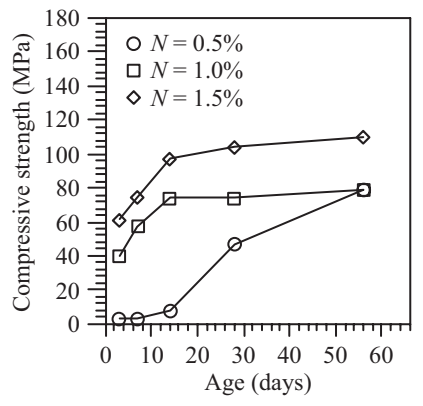

(a) $\mathrm{L} / \mathrm{S}=0.45$

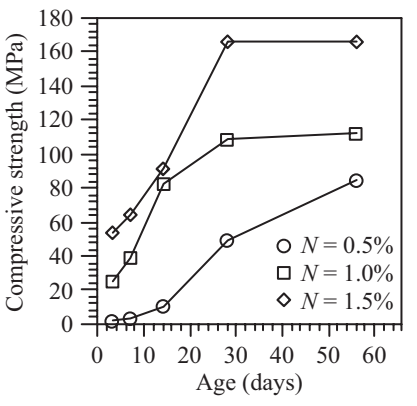

(b) $\mathrm{L} / \mathrm{S}=0.50$

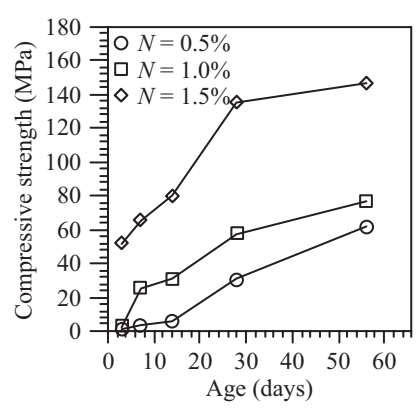

(c) $\mathrm{L} / \mathrm{S}=0.55$

Fig. 3. Compressive strength of each mix group with different $R_{L S}(\mathrm{~L} / \mathrm{S})$.

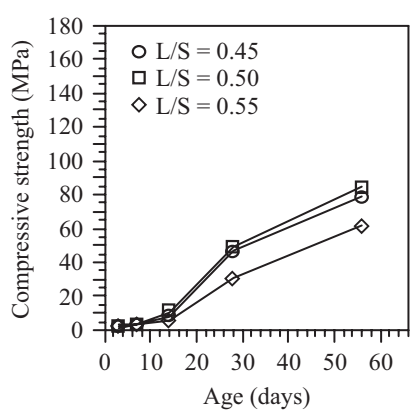

(a) $N=0.5 \%$

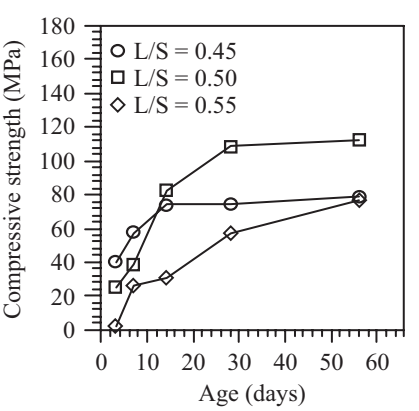

(b) $N=1 \%$

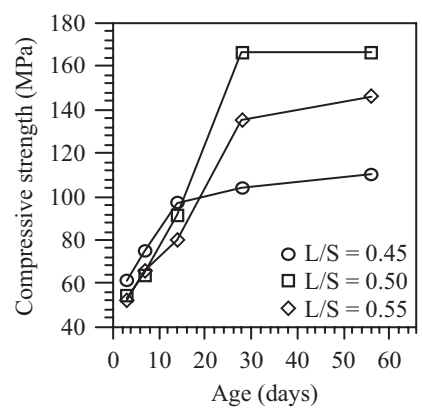

(c) $N=1.5 \%$

Fig. 4. Compressive strength of each mix group with different additions.

to $238.3 \%$. At a fixed value of $N$, it seems that the index of $R_{L S}$ is the key parameter to control the strength. Thus there exists an optimal value of $R_{L S}$ of 0.50 and a significant strength increases when the $N$ value increases to $1.5 \%$ for the mixture set of LS50N15. Unfortunately, Table 5 shows that the 
Table 7. Dynamic elasticity modulus of each mix proportion of alkali-activated GGBFS paste.

\begin{tabular}{lrrrrc}
\hline \multirow{2}{*}{ Designation } & \multicolumn{5}{c}{$\begin{array}{c}\text { Dynamic Modulus of Elasticity (Unit: GPa) } \\
\text { (average of three specimens) }\end{array}$} \\
\cline { 2 - 6 } & 3 days & 7 days & 14 days & 28 days & 56 days \\
\hline LS45N05 & 0.81 & 3.65 & 8.65 & 18.24 & 26.04 \\
LS45N10 & 18.05 & 19.68 & 24.94 & 26.40 & 27.95 \\
LS45N15 & 17.79 & 21.21 & 23.40 & 24.72 & 26.37 \\
LS50N05 & 1.58 & 3.99 & 4.14 & 17.57 & 21.30 \\
LS50N10 & 6.25 & 20.04 & 23.09 & 23.52 & 26.33 \\
LS50N15 & 17.32 & 21.17 & 22.96 & 24.21 & 25.70 \\
LS55N05 & 1.12 & 2.47 & 2.82 & 5.54 & 20.81 \\
LS55N10 & 3.05 & 12.36 & 16.76 & 17.34 & 22.07 \\
LS55N15 & 17.05 & 17.75 & 17.93 & 20.19 & 24.70 \\
\hline
\end{tabular}

mixture set of LS50N15 also has a shortest setting time of 65 and 80 minutes. In practice, definitely, this mixture set is not the best choice for the practical application. Table 6 also shows that the mixture sets of $N$ of $1.5 \%$ have very high early strengths at 3 days of 51.95 to $61.18 \mathrm{MPa}$ and a longer setting times of 170 and 185 minutes, respectively, for mixture set of LS55N15. This mixture is apparently suitable for repair work. The compressive strengths for six mixtures with $R_{L S}$ of 0.50 and 0.55 have increased substantially from 3 to 28 days. After 28 days, the compressive strengths for mixtures with $N=1.0$ and $1.5 \%$ remain roughly constant. It is interesting to note that this phenomenon of polycondensation mechanism of alkali-activated GGBFS paste is quite similar to the hydration mechanism of Portland cement paste.

\section{Dynamic Modulus of Elasticity}

The results of dynamic modulus of elasticity tests on various mixes at ages of 3, 7, 14, 28 and 56 days are summarized in Table 7 and shown in Figs. 5 and 6. Among three mixture sets of $N=0.5,1.0$ and $1.5 \%$, the highest values of dynamic moduli of elasticity of $27.95,26.33$ and $22.07 \mathrm{GPa}$ roughly occur at $N=1.0 \%$. On the other hand, among three mixture sets of $R_{L S}=0.45,0.50$ and 0.55 , the highest values of dynamic moduli of elasticity of $26.04,27.95$ and $26.37 \mathrm{GPa}$ occur at $R_{L S}=0.45$. Thus there exists an optimal combination of $R_{L S}$ and $N$ values to have a highest dynamic modulus of elasticity. But, unlike the considerable increase ratio of compressive strength, the increase ratios here are only between 7.3 and $26.7 \%$. The dynamic moduli of elasticity of alkali-activated GGBFS paste are not very sensitive to the variations of $R_{L S}$ and $N$. Furthermore, the relation between compressive strengths and dynamic modulus of elasticity for alkali-activated GGBFS paste is not closely correlated.

\section{Coefficient of Thermal Conductivity and Volumetric Heat Capacity}

Both test results of the coefficient of thermal conductivity and volumetric heat capacity for alkali-activated GGBFS paste at age of 28 days are shown in Tables 8, 9 and Fig. 7(a)

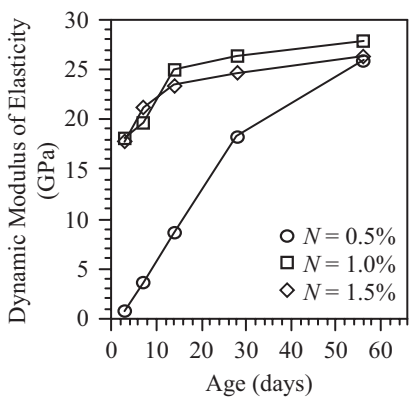

(a) $\mathrm{L} / \mathrm{S}=0.45$

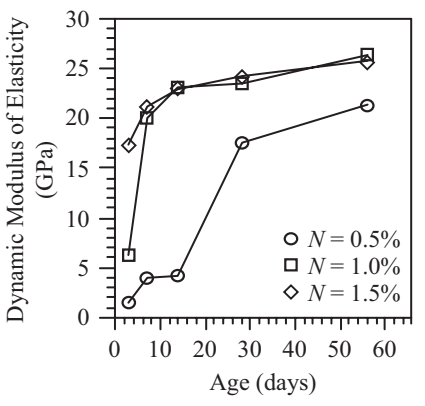

(b) $\mathrm{L} / \mathrm{S}=0.50$

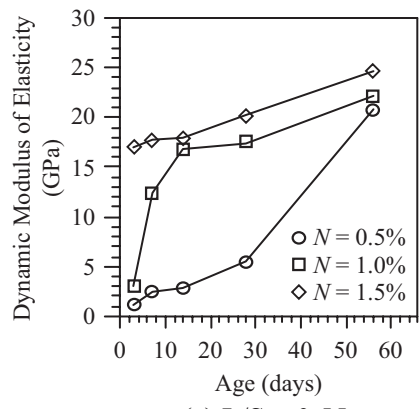

(c) $\mathrm{L} / \mathrm{S}=0.55$

Fig. 5. Dynamic modulus of elasticity of each mix group with different $\boldsymbol{R}_{L S}(\mathbf{L} / \mathbf{S})$.

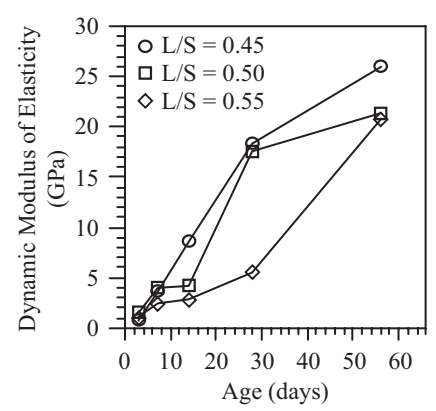

(a) $N=0.5 \%$

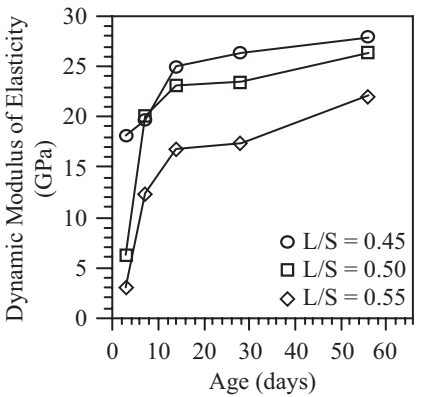

(b) $N=1 \%$

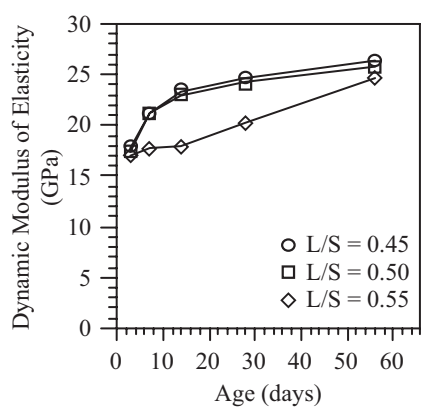

(c) $N=1.5 \%$

Fig. 6. Dynamic modulus of elasticity of each mix group with different additions.

and 7(b). When the added amount of sodium oxide is increased from 0.5 to $1.5 \%$ and the liquid to solid ratio $\left(R_{L S}\right)$ from 0.45 to 0.55 , the maximum increase ratio of coefficients of thermal conductivity is $35.2 \%$ (from 0.585 to 0.791 
Table 8. Coefficient of thermal conductivity of alkaliactivated GGBFS paste with different $R_{L S}$ and $N$.

\begin{tabular}{|c|c|c|c|c|c|c|}
\hline & \multicolumn{2}{|c|}{$R_{L S}=0.45$} & \multicolumn{2}{|c|}{$R_{L S}=0.50$} & \multicolumn{2}{|c|}{$R_{L S}=0.55$} \\
\hline & avg* & $\mathrm{s}^{* *}$ & avg* & $\mathrm{s}^{* * *}$ & avg* & s** \\
\hline$N=0.5$ & 0.691 & 0.021 & 0.608 & 0.005 & 0.585 & 0.010 \\
\hline$N=1.0$ & 0.787 & 0.004 & 0.764 & 0.003 & 0.762 & 0.013 \\
\hline$N=1.5$ & 0.791 & 0.001 & 0.781 & 0.003 & 0.773 & 0.004 \\
\hline
\end{tabular}

Note: * avg indicates the average value of observations.

** $\mathrm{s}$ indicates the standard deviation of observations.

Table 9. Volumetric heat capacity of alkali-activated GGBFS paste with different $R_{L S}$ and $N$.

\begin{tabular}{|c|c|c|c|c|c|c|}
\hline & & & & & \multicolumn{2}{|c|}{$\left(\right.$ Unit: $\left.\mathrm{J} / \mathrm{m}^{3} \cdot \mathrm{K}\right)$} \\
\hline & \multicolumn{2}{|c|}{$R_{L S}=0.45$} & \multicolumn{2}{|c|}{$R_{L S}=0.50$} & \multicolumn{2}{|c|}{$R_{L S}=0.55$} \\
\hline & avg* & $\mathrm{s} * *$ & avg* & $\mathrm{s} * *$ & avg* & $\mathrm{s} * *$ \\
\hline$N=0.5$ & 1.678 & 0.016 & 1.653 & 0.006 & 1.583 & 0.006 \\
\hline$N=1.0$ & 1.712 & 0.028 & 1.663 & 0.006 & 1.595 & 0.009 \\
\hline$N=1.5$ & 1.800 & 0.010 & 1.782 & 0.004 & 1.710 & 0.027 \\
\hline
\end{tabular}

Note: * avg indicates the average value of observations.

** $\mathrm{s}$ indicates the standard deviation of observations.

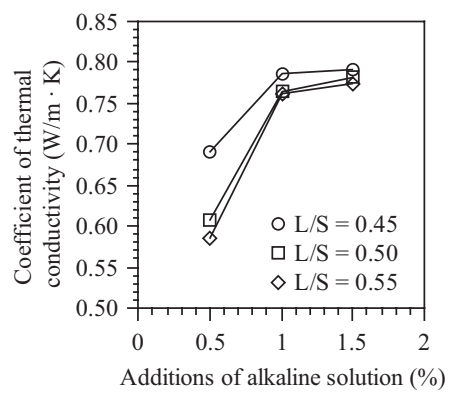

(a) Coefficient of thermal conductivity

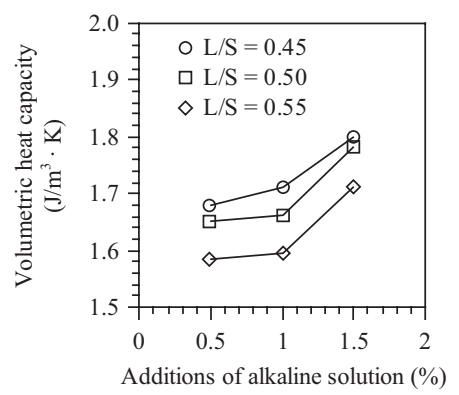

(b) Volumetric heat capacity

Fig. 7. Thermal properties of alkali-activated GGBFS paste with different $\boldsymbol{R}_{L S}$ values and additions of alkaline solution: (a) Coefficient of thermal conductivity, (b) Volumetric heat capacity.

$\mathrm{W} / \mathrm{m} \cdot \mathrm{K})$, and the maximum increase ratio of volumetric heat capacity is $13.7 \%$ (from 1.583 to $1.800 \mathrm{~W} / \mathrm{m} \cdot \mathrm{K}$ ). The highest coefficients of thermal conductivity of $0.791 \mathrm{~W} / \mathrm{m} \cdot \mathrm{K}$ is lower than that of $2.5 \mathrm{~W} / \mathrm{m} \cdot \mathrm{K}$ and the highest volumetric heat

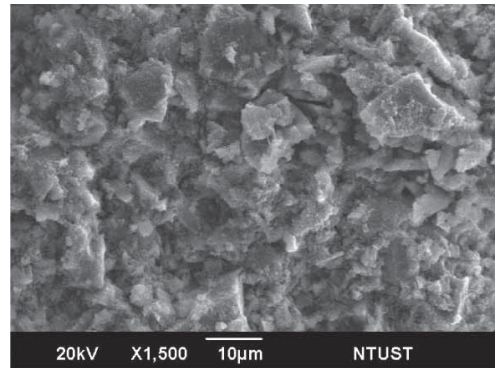

(a) $N=0.5 \%$

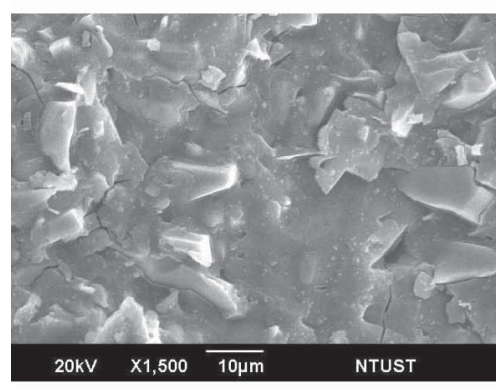

(b) $N=1 \%$

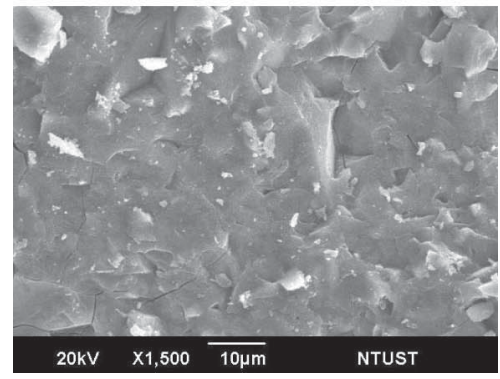

(c) $N=1.5 \%$

Fig. 8. Typical microstructure of alkali-activated GGBFS paste with $\boldsymbol{R}_{L S}$ of $\mathbf{0 . 4 5}$ and different additions of alkaline solution.

capacity of $1.8 \mathrm{~J} / \mathrm{m}^{3} \cdot \mathrm{K}$ is close to that of $2.06 \mathrm{~J} / \mathrm{m}^{3} \cdot \mathrm{K}$ for normal weight concrete [12]. Thus alkali-activated GGBFS paste can be used as a proper material for heat insulation and fire resistance of building construction.

\section{Microstructure of Alkali-Activated GGBFS Paste}

Typical photos of microstructures of alkali-activated GGBFS paste with $R_{L S}$ of 0.45 and different amounts of added sodium oxide are shown in Fig. 8. The porosity of microstructure is gradually reduced, as shown in Fig. 8(a), (b) and (c), when the amount of added sodium oxide is increased from 0.5 to $1.5 \%$. The characteristics of these microstructural variations of porosity structure could explain the beneficial improvement on the compressive strengths and dynamic elasticity moduli of alkali-activated GGBFS paste with the increased amount of added sodium oxide in the alkaline solution. Accordingly, the coefficient of thermal conductivity and volumetric heat capacity are increased as well.

Previous experimental results have shown that the smallest coefficients of thermal conductivity occurred as $N=0.5 \%$. 


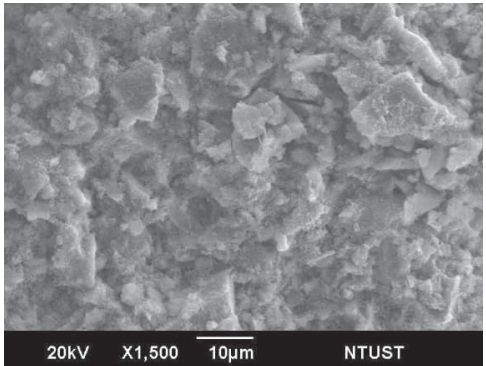

(a) LS45N05

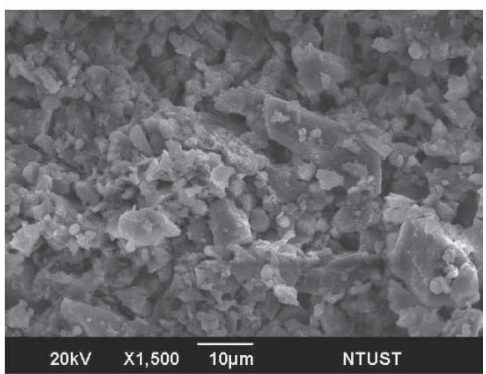

(b) LS50N05

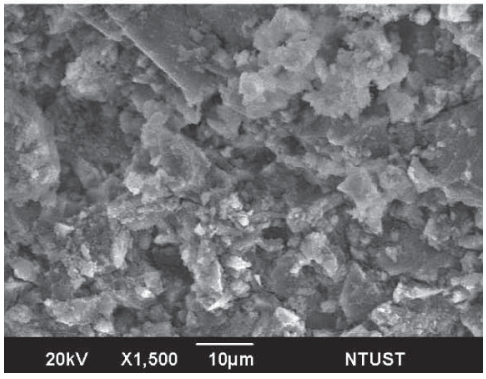

(c) LS55N05

Fig. 9. Typical microstructure of alkali-activated GGBFS paste with different ratios of liquid to solid $(N=0.5 \%)$.

Fig. 9(a), (b) and (c) show the microstructure of alkaliactivated GGBFS paste with $N$ of $0.5 \%$ and $R_{L S}$ of $0.45,0.50$ and 0.55 , respectively. These micrographs clearly show that a large portion of voids has formed in the microstructure of alkali-activated GGBFS paste and could also explain the cause of its low compressive strength, dynamic modulus of elasticity, coefficient of thermal conductivity and volumetric heat capacity as shown in the Fig. 4(a), 6(a), 7(a) and 7(b).

\section{CONCLUSIONS}

Based on the experimental results and microstructural analyses of alkali-activated GGBFS paste presented in this study, the following conclusions can be drawn:

1. A combined alkaline solution of sodium hydroxide and sodium silicate solution is necessary in the mixture to produce alkali-activated GGBFS paste with adequate workability and other engineering properties, for example, a compressive strength of 166.32 MPa and a dynamic elas- ticity modulus of $27.95 \mathrm{GPa}$ at age of 56 days. Thus, a mixture methodology for such purpose is proposed (about $7 \sim 22 \%$ by weight of sodium hydroxide in the liquid as calculated from Table 4) and verified experimentally to be effective.

2. The polycondensation mechanism of alkali-activated GGBFS paste is quite similar to the hydration mechanism of Portland cement paste, in that, most of the engineering properties for both pastes are well developed at age of 28 days, and keep a steady slow growth until 56 days.

3. The flow values of fresh alkali-activated GGBFS paste monotonically increase with the increases of both the added amount of equivalent sodium oxide $\left(\mathrm{Na}_{2} \mathrm{O}\right)$ and the liquid to solid ratio. However, the initial and final setting times also monotonically increase with the increase of the liquid to solid ratio due to the dilation effects, but substantially decrease with the increase of the added amount of equivalent sodium oxide $\left(\mathrm{Na}_{2} \mathrm{O}\right)$.

4. The compressive strengths of alkali-activated GGBFS paste at all five ages will monotonically increase with the increase of added amount of equivalent sodium oxide $\left(\mathrm{Na}_{2} \mathrm{O}\right)$ of alkaline solution in the mixture where a highest compressive strength of 166.32 MPa was found. However, increase of $\mathrm{Na}_{2} \mathrm{O}$ in the mixture also notably expedites both the initial and final setting times of the paste to almost a same short 10 minutes such that its practicability may be thus limited.

5. An optimal value of liquid to solid ratio of about $50 \%$ of the mixture was found to have the higher compressive strength achieve to $166.32 \mathrm{MPa}$, that indicates that the effect of interaction between the amount of sodium oxide and the liquid to solid ratio on the chemical mechanism of strength development is worthy of further investigation in the future.

6. The dynamic moduli of elasticity of alkali-activated GGBFS paste are not very sensitive to the variations of the amount of equivalent sodium oxide and the liquid to solid ratio. Furthermore, the relation between compressive strengths and dynamic modulus of elasticity for alkali-activated GGBFS paste is not closely correlated.

7. The alkali-activated GGBFS paste has better thermal properties compared with those of normal weight concrete and thus can be used as a proper material for heat insulation and fire resistance of building construction.

8. The denser the microstructure of alkali-activated GGBFS paste is, the higher its compressive strength, dynamic modulus of elasticity, coefficient of thermal conductivity and volumetric heat capacity will be.

\section{ACKNOWLEDGMENTS}

This work was carried out under the financial supports of the Taiwan Building Technology Center (TBTC) of National Taiwan University of Science and Technology (Taiwan Tech). Courtesy of some experimental data from Mr. Wei-Lun Lin is also appreciated. 


\section{REFERENCES}

1. Akyuz, S. and Oner, A., "An experimental study on optimum usage of GGBS for the compressive strength of concrete," Cement and Concrete Composites, Vol. 29, No. 6, pp. 505-514 (2007).

2. Benazzouk, A., Douzane, O., Mezreb, K., Laidoudi, B., and Quéneudec, M., "Thermal conductivity of cement composites containing rubber waste particles: Experimental study and modeling," Construction and Building Materials, Vol. 22, No. 4, pp. 573-579 (2008).

3. Boukendakdji, O., Kenai, S., Kadri, E. H., and Rouis, F., "Effect of slag on the rheology of fresh self-compacted concrete," Construction and Building Materials, Vol. 23, No. 7, pp. 2593-2598 (2009).

4. Bribián, I. Z., Capilla, A. V., and Usón, A. A., "Life cycle assessment of building materials: Comparative analysis of energy and environmental impacts and evaluation of the eco-efficiency improvement potential," Building and Environment, Vol. 46, No. 5, pp. 1133-1140 (2011).

5. Brough, A. R., Holloway, M., Sykes, J., and Atkinson, A., "Sodium silicate-based alkali-activated slag mortars: Part II. The retarding effect of additions of sodium chloride or malic acid," Cement and Concrete Research, Vol. 30, No. 9, pp. 1375-1379 (2000).

6. Davidovits, J., "Geopolymer chemistry and sustainable development, the poly (sialate) terminology: a very useful and simple model for the promotion and understanding of green-chemistry," Proceedings of 2005 Geopolymere Conference, Géopolymèr Institute, Saint-Quentin, France, pp. 9-15 (2005).

7. Davidovits, J., Geopolymer Chemistry and Applications, Géopolymèr Institute, Saint-Quentin, France, pp. 19-36 (2008).

8. Holman, J. P., Heat Transfer, McGraw-Hill Book Co., New York (1986).

9. Komnitsas, K., Zaharaki, D., and Perdikatsis, V., "Effect of synthesis parameters on the compressive strength of low-calcium ferronickel slag inorganic polymers," Journal of Hazardous Materials, Vol. 161, Nos. 2-3, pp. 760-768 (2009).

10. Li, C., Sun, H., and Li, L., "A review: The comparison between alkali-activated slag $(\mathrm{Si}+\mathrm{Ca})$ and metakaolin $(\mathrm{Si}+\mathrm{Al})$ cements," Cement and Concrete Research, Vol. 40, No. 9, pp. 1341-1349 (2010).

11. Lin, W.-L., "Study on Engineering Properties of Alkali-Activated Slag Pastes," Master Thesis, Department of Construction Engineering, National Taiwan University of Science and Technology (2009). (in Chinese)

12. Mindess, S., Young, J. F., and Darwin, D., Concrete, 2nd Edition, Prentice Hall, New Jersey, U.S.A. ( 2002).
13. Mohamed, I. O., "Simultaneous estimation of thermal conductivity and volumetric heat capacity for solid foods using sequential parameter estimation technique," Food Research International, Vol. 42, No. 2, pp. 231-236 (2009).

14. Mozgawa, W. and Deja, J., "Spectroscopic studies of alkaline activated slag geopolymers," Journal of Molecular Structure, Vols. 924-926, pp. 434-441 (2009).

15. Nazari, A. and Riahi, S., "The effects of $\mathrm{TiO}_{2}$ nanoparticles on physical, thermal and mechanical properties of concrete using ground granulated blast furnace slag as binder," Materials Science and Engineering: A, Vol. 528, Nos. 4-5, pp. 2085-2092 (2011).

16. Oh, J. E., Monteiro, P. J. M., Jun, S. S., Choi, S., and Clark, S. M., "The evolution of strength and crystalline phases for alkali-activated ground blast furnace slag and fly ash-based geopolymers," Cement and Concrete Research, Vol. 40, No. 2, pp. 189-196 (2010).

17. Temuujin, J., Rickard, W., Lee, M., and Riessen, A., "Preparation and thermal properties of fire resistant metakaolin-based geopolymer-type coatings," Journal of Non-Crystalline Solids, Vol. 357, No. 5, pp. 13991404 (2010).

18. United Nations, Agenda 21, United Nations Conference on Environment and Development (UNCED), UN General Assembly, Rio de Janeiro, Brazil (1992).

19. Van Jaarsveld, J. G. S. and Van Deventer, J. S. J., "Effect of the alkali metal activator on the properties of fly ash-based geopolymers," Industrial Engineering Chemical Research, Vol. 38, No. 10, pp. 3932-3941 (1999).

20. Vejmelková, E., Keppert, M., Grzeszczyk, S., Skaliński, B., and Černýa, R., "Properties of self-compacting concrete mixtures containing metakaolin and blast furnace slag," Construction and Building Materials, Vol. 25, No. 3, pp. 1325-1331 (2011).

21. Xu, H. and Van Deventer, J. S. J., "The geopolymerisation of alumino-silicate minerals," International Journal Minerals Process, Vol. 59, No. 3, pp. 247-266 (2000).

22. $\mathrm{Xu}, \mathrm{Y}$. and Chung, D. D. L., "Effect of sand addition on the specific heat and thermal conductivity of cement," Cement and Concrete Research, Vol. 30, No. 1, pp. 59-61 (2000).

23. Zhang, Z., Yao, X., and Zhu, H., "Potential application of geopolymers as protection coatings for marine concrete: I. Basic properties," Applied Clay Science, Vol. 49, Nos. 1-2, pp. 1-6 (2010). 